\title{
DISPOSITIVOS CINEMATOGRÁFICOS NO PROCESSO DE ENSINO APRENDIZAGEM EM SOCIOLOGIA NO IFPB/JAGUARIBE: diálogos e práticas possíveis
}

\section{CINEMATOGRAPHIC DEVICES IN THE TEACHING-LEARNING PROCESS IN SOCIOLOGY AT IFPB - JAGUARIBE: possible dialogues and practices}

Paula Cristina Tenorio Cavalcante*

\section{Resumo}

Este relato tem por objetivo ampliar as discussões sobre como o cinema pode contribuir no processo de ensino-aprendizagem de sociologia, a partir das concepções da Lei 13.006/2014 e das lacunas formadas na práxis do cumprimento da lei nas escolas da rede pública. E com isto, apresentar os resultados obtidos ao longo do estágio realizado nas aulas do Ensino Médio Técnico Integrado no Instituto Federal da Paraíba (IFPB) Jaguaribe/PB, por meio do Programa de Incentivo à Docência (PIBID) Sociologia que ocorreu em 2019. Trata-se de narrar e refletir sobre os potenciais pedagógicos de dispositivos cinematográficos no ensino de sociologia.

Palavras-chave: Sociologia; Cinema; Educação; Direitos Humanos.

\section{Abstract}

The aim of this report is to extend discussion regarding the manner in which cinema can contribute to the teaching-learning process of Sociology in public schools, deriving from government decree 13.006/2014 and the problems encountered in complying with it. The results presented were obtained during an internship in 2019 at an Integrated Technical High School at the Federal Institute of Paraíba (IFPB)/Brazil, through participation in the Program for Teacher Initiation (PIBID). It deals with an attempt to narrate and reflect upon the pedagogic potential of cinematographic devices in the teaching of sociology.

Keywords: Sociology, Cinema, Education, Human Rights.

\section{Introdução}

O ambiente escolar é responsável não só pelo processo de ensino e aprendizagem, é também o palco importante de relações e contatos com as diferentes visões de mundo que crianças e jovens possuem. Creio que, nesse cenário, a arte tem um papel fundamental. Em 2008, o senador Cristovam Buarque propôs o Projeto de Lei 185, que posteriormente ficou conhecido como PL 7.507/2010 — base para a Lei 13.006/2014,

\footnotetext{
* Aluna do Curso de Licenciatura em Ciências Sociais Licenciatura pela UFPB/Brasil; bolsista do Programa de Incentivo à Docência (PIBID) Sociologia. E-mail: paula.tcavalcante@gmail.com
} 
sancionada pela ex-presidente Dilma Rousseff —, no qual destacava a importância de políticas públicas voltadas à pesquisa e à prática da arte cinematográfica, com destaque para sua inserção no ambiente escolar. Segundo Barra (2016, p. 7782), a justificativa para o PL 7.507/2010 apresentada pelo senador, na época de sua proposta, confere um lugar especial à indústria cinematográfica nacional.

A aprovação da Lei 13.006/2014 (BRASIL, 2014) possibilitou maior visibilidade e incentivo à produção cinematográfica nacional, no entanto, a garantia de espectadores nas salas de cinema para produções nacionais financiada pela União, não serviu eficientemente como alicerce para a proposição do trabalho com o cinema e educação nas escolas. O "cinema na escola" precisa ser concebida como uma atividade na qual os jovens possam experimentar, de forma regular, a vivência com o cinema na intensidade do assistir e do fazer.

Muitos são os questionamentos sobre de que maneira o ensino e a exibição de cinema nas escolas de ensino básico no país se desenrolam. Será que esta lei garante a exibição dos filmes de produção nacional nas escolas do país? Quais critérios são utilizados para essa seleção? A quem cabe defini-los? Quem propõe as atividades com o cinema na escola? Quais as orientações que o professor precisa ter para trabalhar com o cinema e ser capaz de operacionalizar as exibições? De que forma isto se processa?

Observo que a escola pública está submetida a um processo de esvaziamento de sentidos, sua eficiência é medida pela quantidade do que é oferecido, colocando sob suspeita a competência profissional de seus professores, os quais fazem parte de um sistema que os operacionaliza para planejar aula, usar certos tipos limitados de materiais e de avaliações de aprendizagem.

Migliorin e Fresquet apostam na necessidade e na importância da presença do cinema na escola, pautados em três aspectos:

$1^{\text {a }) ~ a ~ d i m e n s a ̃ o ~ p o l i ́ t i c a ~ e ~ e s t e ́ t i c a ~ d o ~ c i n e m a, ~ o u ~ s e j a, ~ a c r e d i t a r ~ n o ~ c i n e m a ~ e ~ n a ~}$ sua possibilidade de intensificar as invenções de mundo; $2^{\mathrm{a}}$ ) apostar no cinema na escola como espaço em que o risco dessas invenções de tempo e espaço é possível e desejável, com toda a perturbação que isso possa significar; $3^{a}$ ) considerar que as crianças e os jovens são a condição necessária para que exista a relação cinema/escola (MIGLIORIN; FRESQUET, 2015 apud BARRA, 2016, p. 7786) 
A presença do cinema na escola não só promove o movimento das pessoas no espaço, como também interfere nos processos de construção pessoal e coletiva, objeto da sociologia.

\begin{abstract}
Martins (2009, p. 47) acredita que a sociologia pode encontrar grande riqueza na informação visual, porém exige cuidado para não tomar a imagem, tal qual a palavra falada, como documento social em termos absolutos porque existe a dificuldade de sua insuficiência e suas limitações.

Sociólogos e antropólogos incorporaram as imagens no arcabouço de técnicas de investigação que pressupõem como recursos técnicos equivalentes à sociedade, o verbalizável, o memorável, o escrevível e o visível. Contudo, a sociedade também se move a partir do indizível e do invisível. A imagem fotográfica, e suas variantes, no filme e no vídeo, podem substituir o próprio indivíduo na reprodução das relações sociais; a imagem é objeto e também sujeito (RACHETTI, 2016, p. 60).
\end{abstract}

O desafio aqui fora encontrar o caminho entre a realidade palpável da experiência viva da dimensão pedagógica do pensar cinematograficamente e a práxis do ensino de sociologia, em um espaço onde a imagem é tida como o completo oposto. Pensar sociologicamente por meio do cinema, é um desafio do visível e do invisível, do palpável e do não-palpável.

\title{
Regulamentação da lei 13.006/2014 nas escolas
}

A Lei 13.006/2014 (BRASIL, 2014) representou um marco histórico para o diálogo direto e para contribuições efetivas na construção de possibilidades e propostas de acesso ao cinema brasileiro, um país de dimensões continentais. Observa-se que ela incide em três pontos: a obrigatoriedade de exibição de produção audiovisual nacional nas escolas de educação básica, estabelecendo quantidade mínima de tempo; a exibição como constituinte de componente curricular complementar; e sua integração à proposta pedagógica da escola. Segundo o senador Cristovam Buarque, os jovens que não têm acesso às obras cinematográficas ficam privados de um dos objetivos fundamentais da educação: o desenvolvimento do senso crítico (BARRA, 2016, p. 7782).

Ter acesso às obras cinematográficas, a elas assistir, conhecê-las, viver o prazer da fruição e expor-se às emoções imprevisíveis que suscitam, possibilita ir além do desenvolvimento do senso crítico. Embora por mais legítimo que seja a afirmação pelo direito à fruição da arte nas escolas, segundo o senador, seu discurso tem rebatimento na revolução tecnológica da última década, que hoje proporciona acesso às redes e a plataformas de streaming que, de certa forma, garantem e "democratizam" o acesso às 
produções cinematográficas. Porém, essa realidade refere-se a determinado público, visto que muitos dos jovens do ensino básico da rede pública, sequer têm acesso a outras propostas de ensino das artes dentro e fora das escolas, por conta das próprias políticas pedagógicas das instituições, e pela condição de classe que eles ocupam. É nítido que o senador se refere a uma classe de estudantes claramente privilegiados economicamente.

No entanto, nem o senador Cristovam e nem ninguém esclareceu quais os critérios para a garantia da atuação do cinema nas escolas, nem tão pouco, de que maneira o custeamento e financiamento de toda a infraestrutura necessária seria feito, deixando uma lacuna na execução da Lei 13.006/2014, o que me traz a esta reflexão: de que maneira é conduzida a garantia da Lei 13.006/2014 nas escolas da rede pública? Há infraestrutura adequada para tal? A resposta, infelizmente, sem grandes surpresas: nenhuma.

\section{Inventando com a diferença}

A escola deve ser um espaço de ampliação da produção e do repertório cultural discente e docente, lugar de democratização do conhecimento artístico, ambiente de produção, circulação e fruição da cultura brasileira.

Por meio de inúmeras reflexões, ao longo das reuniões com a equipe do Programa de Incentivo à Docência (PIBID), composta pelos alunos bolsistas, além de seus coordenadores, a professora Rita de Cássia Melo Santos (UFPB) e o professor Adolfo Wagner (IFPB), fui construindo a ideia de relacionar a utilização dos dispositivos cinematográficos — temática dos "Cadernos do inventar" — com as aulas de sociologia que estava acompanhando no Instituto. A primeira vista, o ensejo seria a aplicação de sete dispositivos cinematográficos escolhidos por mim, que seriam desenvolvidos com o(a)s aluno(a)s em horários alternados, durante os intervalos de aula, e aberta a todo(a)s que se interessassem pelos temas previamente delimitados: gênero, raça, povos indígenas, violência na escola. No entanto, devido a alguns problemas, como a falta de infraestrutura adequada, ausência/desinteresse dos próprios alunos e o cronograma pedagógico do Instituto, as oficinas não se realizaram.

\footnotetext{
${ }^{1}$ Material didático desenvolvido pelo Projeto Inventar com a Diferença - cinema, educação e direitos humanos, ligado à Universidade Federal Fluminense com a finalidade de desenvolver ações e projetos que visem à democratização do cinema, educação e direitos humanos. Ver: http://www.inventar comadiferenca.com.br/
} 
A partir das premissas de que a atividade cinematográfica não precisa ser restrita a uma atividade cineclubista, e que os dispositivos cinematográficos, tal como são propostos no "Cadernos do inventar com a diferença", podem ser utilizados como ferramenta pedagógica a partir da criação cinematográfica no espaço escolar.

Dispositivos são exercícios, jogos, desafios com o cinema, um conjunto de regras para que o estudante possa lidar com os aspectos básicos do cinema e, ao mesmo tempo, se colocar, inventar com ele, descobrir sua escola, seu quarteirão, contar suas histórias. Há dois modelos de dispositivos: aquele com equipamento de filmagem e gravação de som e aquele sem equipamento (MIGLIRORIN et al., 2016, p. 10).

A proposta pedagógica que construí, pensando no cenário escolar do IFPB/PB, baseia-se no "Cadernos do inventar" (MIGLIRORIN et al., 2016), mostrando sete passos que guiam metodologicamente a utilização prática e a observação dos usos dos dispositivos. São os seguintes: cenas de emancipação, descoberta de um território, engajamento no conhecimento, inquietação e revolta, fagulha de identidade, descoberta de uma potência criativa, abertura à diferença em um processo subjetivo.

Estas propostas pedagógicas dão um caráter social às práticas, pois cada uma delas traz, metodologicamente, ferramentas para que os alunos e alunas possam agir de maneira participativa em seu território. Conceber o(a) aluno(a) como sujeito, possibilita-lhe uma presença ativa no processo de produção e conhecimento: pesquisar, perguntar, conversar para explorar novas perspectivas. Incentivado e envolvido, ele(a) se sentirá responsável e comprometido com o que está aprendendo e produzindo. A partir do momento que o(a) aluno(a) se sente parte do todo, ele(a) torna-se um sujeito preparado para reagir às demarcações sociais rígidas, que comandam as formas de vida, admitidas e silenciadas dentro de uma comunidade.

Possibilitam experimentar o processo de produção, de forma que "qualquer" pessoa vindo de "qualquer" lugar, possa contribuir, caracterizando-o como espaço de troca de saberes. É necessário, então, deslocar-se dos papéis tradicionais para facilitar a troca. A proposta contribui, acima de tudo, para que os alunos e alunas tenham suas próprias convicções e percepções desestabilizadas a partir do contato com as diferenças, e possam experimentar as possibilidades de reflexão que o trabalho com a arte proporciona. 


\section{O olhar cinematográfico e a sociologia}

No aspecto da utilização da linguagem cinematográfica no ensino de sociologia para alunos do ensino médio, segundo Martins,

o filme pode reconstruir a realidade num dado contexto histórico e que a destarte, seja um modo de compreender comportamentos, visões de mundo e ideologias em uma sociedade. Fruto de um imaginário, o filme não é um reflexo do real, é uma produção que age sobre imaginários e que suscita questões cotidianas a serem discutidas. Assim, o contexto social em que as imagens foram criadas e o contexto em que elas forem vistas que denotam significado a elas (MARTINS 2007 apud RACHETTI, 2016, p. 61).

A indicação de filmes para exibição em sala de aula é prática existente há alguns anos nos livros didáticos de sociologia propostos pelo Programa Nacional do Livro e Material Didático (PNLD), ${ }^{2}$ incluem imagens e temas interdisciplinares e transversais para serem trabalhados com recursos imagéticos.

No Instituto Federal da Paraíba (IFPB), não é diferente, o livro didático adotado para o ensino de sociologia, possui, nos seus 15 capítulos, sugestões de filmes de acordo com cada tema trabalhado nos capítulos, organizadas pelo título da obra e demais elementos referenciais (país, direção, duração e sinopse do filme). ${ }^{3} \mathrm{O}$ material apresentado no corpo do livro passa a orientação fílmica exclusivamente como uso diretivo, ou seja, utiliza-se a indicação de filmes e exibição de produções cinematográficas em sala de aula, apenas como complemento do tema trabalhado, mostrando dentro do possível - de acordo com a seleção que o/a educador/a possa vir a fazer -, as diferentes possibilidades e construção de contextos existentes na realidade social, ou como recurso visual de construção de imagens dentro de um cenário sóciohistórico.

No entanto, a utilização dos dispositivos cinematográficos serviu como guia para a construção e planejamento das atividades desenvolvidas cuja experiência estou relatando. Parti do princípio da utilização da experiência fílmica, não somente como exibição/audiência, mas principalmente como prática, o que passo a relatar.

\footnotetext{
${ }^{2}$ Programa do Governo Federal que envolve ações de escolha e distribuição de obras didáticas, pedagógicas e literárias, além de outros materiais de apoio à prática educativa, para alunos e professores das escolas públicas de educação básica do país. Ver: https://www.fnde.gov.br/programas/programas-do-livro.

${ }^{3}$ O livro referência para o ensino de sociologia no IFPB: Sociologia em movimento de Afrânio Silva e colaboradores (SILVA et al, 2016).
} 
A professora de sociologia Suely Paula do IFPB, coordenadora de um projeto de extensão desenvolvido na Escola Estadual Pedro Augusto Porto Caminha (EEPAC), convidou-me para ministrar uma aula à turma de $2^{\circ}$ ano do ensino médio dessa escola. Atividade aconteceu no dia 27 de agosto de 2019. Preparei a aula para a aplicação de um dispositivo cinematográfico, com a exibição do documentário chamado "Território do Brincar" (TERRITÓRIO, 2015). Iniciei me apresentando: quem eu era, o que fazia e porque estava ali.

Sugeri aos alunos que também se apresentassem. Assim foi. À guisa de contextualização: o colégio EEPAC é uma escola de ensino público fundamental e médio que, assim como muitas escolas Brasil a fora, sofre com questões de infraestrutura, descaso de funcionários, abandono dos estudantes, vandalismo e casos afins. Neste mesmo dia da oficina, acontecia uma reforma nas instalações físicas do prédio, que, conforme me disseram os alunos, durava meses. Ao chegar à escola, fui à sala dos professores para pegar o único e essencial material que precisaria: uma TV. Na ocasião, ela estava guardada em alguma parte no meio da reforma, foi, então, devidamente limpa e instalada na sala para que a aula pudesse se desenvolver.

Seguindo com a atividade, iniciei com a pergunta que norteia este projeto: "Você já se pensou produzindo cinema?"

Dentre os olhares curiosos, provocados pela pergunta e por aquela que lhes falava, foram surgindo respostas como "nunca pensei”, “sim, já fiz teatro", “já participei de um coletivo que produziu vídeos". No conjunto, a conversação foi se deslanchando e a sala de aula se preencheu com um novo ar: o da curiosidade. De se ver pensando e sendo desafiado por um novo olhar: o da câmera de celular, na frente e atrás dela.

Propus aos estudantes que, inspirados pelo dispositivo intitulado "Foto Falada", ${ }^{4}$ fossem divididos em grupos, e produzissem um vídeo de aproximadamente três minutos com o tema "Cotas Raciais", tema o qual já havia sido discutido com a turma nas atividades do projeto de extensão coordenado pela professora Suely Paula. Três vídeos foram produzidos, sendo que não lhes dei nenhuma orientação padronizada de como

\footnotetext{
${ }^{4}$ Dispositivo criado pelo projeto "Rolezinho na UFPB" que é realizado no Porto do Capim/PB e na Universidade Federal da Paraíba, por meio do projeto Sementes Cinematográficas, inspirado no dispositivo "Foto Moldura" presente no "Cadernos do inventar" (MIGLIRORIN et al., 2016).
} 
deveria ser a produção, apenas os orientei a construir um roteiro e, no momento da filmagem, que se atentassem aos recursos de enquadramento, ângulo e luminosidade, considerando que se tratava de uma produção fílmica de baixo custo, ou seja, valendo-se da câmera do smartphone como única ferramenta. Os dividi em grupos, e pedi que escrevessem um roteiro a ser usado como base para o que quer que fosse que eles falariam nos vídeos. Cada um foi bem diferente do outro: tivemos diálogos a favor ou contra as cotas raciais, um vídeo mostrando a parte externa da sala de aula onde eles circulam e encenam um caso de racismo na escola, e um terceiro apontando argumentos favoráveis e contrários às cotas raciais ao ingresso na universidade pública.

Diferente da realidade geral das escolas públicas, no IFPB, a condição sobre os equipamentos se torna mais viável, pois nas salas de aula há computador, projetor e tela para exibição de conteúdo, instrumentos que fazem parte do cotidiano de alunos e professores, que deles se utilizam com frequência em sala de aula. Por exemplo, na turma de $1^{\circ}$ ano do curso de Edificações, na disciplina de sociologia, ministrada pelo professor Adolfo Wagner, os alunos tinham como tarefa a apresentação de trabalhos sobre determinados conceitos da sociologia clássica, especificamente, os conceitos de Émile Durkheim. Um dos grupos utilizou a produção de vídeo como ferramenta de trabalho, o que envolveu a produção de tema, roteirização, escolha de cenário, encenação e atores. Foi construído todo um ambiente para a produção, e todo o processo foi feito utilizandose somente as câmeras dos smartphones, desde a captação até a edição, por meio de aplicativos de edição próprio para esse tipo de aparelho.

A experiência nos fez ver que o uso dos dispositivos cinematográficos, como proposta metodológica no ensino em sociologia, torna-se uma ferramenta concreta e viável diante das limitações da realidade escolar que nos cerca: produção de cinema nas escolas a baixo custo, onde o smartphone deixa de ser um "vilão" e passa a ser uma ferramenta importante.

O elemento da criação fílmica é posicionado como um recurso que possibilita
o acesso à memória, aos códigos de determinada cultura, aos processos de
constituição identitária e aos diversos modos de existir e de se relacionar com
a diferença em uma experiência estética de construção de um mundo em
comum (BARQUETE, 2017. p. 99).

Dessa forma, a aplicação das aulas-oficinas de cinema no IFPB é pautada na dimensão do registro fotográfico como uma construção do olhar, que leva à reflexão sobre 
as distintas dimensões e camadas da sociedade: território, identidade, etnia, gênero e classes. Para cada um dos dispositivos corresponde o estímulo ao debate e direção do olhar sociológico, ou como diria Martins (2002), a "imaginação fotográfica" — em referência a W. Mills (1980) —, como estímulo à reflexão sobre as desencontradas temporalidades que nos cercam. Sendo assim, os dispositivos cinematográficos podem funcionar como caminho para a prática da reflexividade ou da imaginação sociológica.

\section{Usando os dispositivos em sala de aula}

Todas as imagens captadas foram produzidas pelos smartphones dos alunos. $\mathrm{O}$ uso do aparelho celular, hoje, é visto como forma de readaptar e reinventar a relação dos adolescentes com o uso das tecnologias, é também a porta de acesso às redes sociais online no geral. A participação nas plataformas virtuais, como espectadores e/ou produtores, tais como Youtube, Instagram, Facebook, Twitter etc. é uma experiência bem difundida entre eles, assim, diante de uma proposta de aprendizado dentro de sala de aula que se utiliza de uma linguagem que eles dominam, torna a atividade didático-pedagógica mais significativa. Não se trata, entretanto, de ensinar-lhes uma nova técnica ou um novo conceito de produção, mas de empoderá-los enquanto sujeitos sociais e jovens estudantes sobre o potencial imagético dos vídeos, sobre a potência de atingir diferentes nichos da sociedade por meio de vídeos criados em sala de aula, utilizando apenas um aparelho que já faz parte do cotidiano deles.

Visto que a primeira proposta de desenvolvimento das oficinas no IFPB não pôde acontecer, a partir de setembro de 2019, passei a planejar as aulas de outra forma: com uma turma apenas, seguindo o planejamento feito pelo professor da disciplina, considerando as temáticas e conceitos que ele deveria trabalhar nas aulas.

Assim, no dia 25 de setembro, acompanhando a turma de $3^{\circ}$ ano do curso de Instrumentos Musicais, iniciei a primeira observação de aula como bolsista PIBID. Nesse dia, o professor começou a fazer uma introdução sobre a Política, apresentando os temas que seriam discutidos ao longo do bimestre. Ele planejou as aulas para apresentação das concepções de Estado e poder, tendo como eixo principal as relações de poder e cotidiano. Na primeira aula, foram tratados temas como: formação de estruturas de Estado, política, formas de poder, território, soberania, Governo e sua finalidade. Ao final da aula, 
apresentei-me à turma e contei sobre a minha proposta de atividade, que seria considerada como nota de uma das avaliações de aprendizagem. Eles deveriam produzir um filmecarta $^{5}$, no qual relatariam a um remetente (imaginário ou real) as impressões que cada grupo possuía sobre as relações de poder dentro do IFPB.

O objetivo principal dessa atividade foi estimular discussões sobre as relações de poder, a partir de conceitos trabalhados em sala de aula, tais como o "micropoder" de Foucault (1979), a relação entre poder e patriarcado de Saffioti (1987), procurando destacar e exemplificar maneiras de como esses conceitos se manifestam nas relações interpessoais e sociais na sociedade e, principalmente, no IFPB.

$\mathrm{Na}$ construção do plano de atividades da aula com os dispositivos cinematográficos, eles seguiram os passos para aplicação do dispositivo: escolher um destinatário (uma pessoa, instituição, local, objeto etc.), assistir ao material (dispositivos) produzidos por outros grupos e/ou encontros, formar os grupos, selecionar, organizar e criar os materiais, capturar as imagens, finalizar e editar, e apresentação do filme-carta.

Todos os passos aconteceram dentro do tempo que tínhamos, foram quatro encontros distribuídos para a generalização dos conceitos de relações de poder, micropoder e patriarcalismo; exibição do vídeo "O que é um filme-carta"; escolha dos temas e debate sobre a escolha do destinatário; finalização da carta; apresentação dos passos para aplicação do dispositivo.

O meu planejamento de aula foi desenvolvido baseado nos pressupostos da Escola Nova, pautando-se em metodologia de aplicação ativa, seguindo os passos: atividade, problema, dados, hipóteses, aplicação. Distribui o tempo de 50 minutos da aula para exibição de uma série de filmes-carta e suas múltiplas possibilidades narrativas, procurando inspirar a turma, de modo que o(a)s aluno(a)s sentissem, de fato, a liberdade para expressar suas impressões e opiniões. Por questões de saúde, o professor Adolfo Wagner precisou ser substituído pela professora Suely Paula, por quem fomos acompanhados (a turma e eu) até o final do cronograma.

\footnotetext{
${ }^{5}$ Filme-carta é um dispositivo cinematográfico presente no "Cadernos do inventar" (MIGLIRORIN et al., 2016) - trata-se de "uma carta imagética" que tem remetente, destinatário e um tema enredo.
} 
Ao final, foram formados cinco grupos. Cada um "escreveu" uma carta para um destinatário, filmou, editou e, por último, no dia 03 de novembro de 2019, realizou-se a exibição das produções.

O grupo 1 tematizou a relação "professor-aluno", tendo como destinatário o IFPB. Destacou certo autoritarismo observado frequentemente na atitude dos professores em relação aos alunos, em segundo plano, eles sentiram a falta de maior interação entre o corpo discente e o IFPB, especialmente, a falta de diálogo com os professores.

O grupo 2 falou sobre a "escola-ideologia", tendo como destinatário também o IFPB, questionando o lugar da ideologia que os professores levam para os alunos em sala de aula. Finalizaram a carta-filme com a questão: "Ideologia é cárcere?"

No grupo 3, os alunos escolheram como destinatário o NACE (Núcleo de Artes, Cultura e Eventos do IFPB), abordando o descaso que, segundo eles, o IFPB tem pelos músicos que tocam na sua orquestra, e o sucateamento dos instrumentos musicais, sem manutenção, quebrados e em número insuficiente.

O grupo 4, que se intitulou "Grupo Adolfo Wagner", abordou a democratização da relação professor-aluno, expondo entrevistas aqueles professores que os alunos consideram essenciais no IFPB para sua formação, por serem abertos ao diálogo, priorizando relações não hierárquicas com os alunos.

O grupo 5 (na verdade, composto apenas por uma aluna) escolheu para destinatário o diretor do IFPB. No seu filme-carta, declama um poema de sua autoria, no qual narra seus anseios para o futuro, para a escola e o país, e pede que os "superiores" tenham mais empatia com as demandas dos adolescentes.

Após as exibições, dialogamos sobre as expectativas e impressões que o(a)s aluno(a)s tiveram da atividade. Como resposta, obtivemos alguns depoimentos como este: — Foi muito bom aprender sobre política e como as relações de poder estão nas nossas vida por intermédio do cinema, e poder fazer isso a gente mesmo. ${ }^{6}$

Houve muitos resultados positivos com a utilização desse dispositivo, que atingiram cada um (incluindo a professora) de uma maneira diferenciada, de acordo com a realidade e lugar de fala. A professora Suely se sentiu motivada com os resultados,

\footnotetext{
${ }^{6}$ Masculino, 16 anos de idade.
} 
principalmente com o envolvimento positivo dos alunos na dedicação em pesquisar, refletir e produzir um filme-carta, o que a fez pensar na possibilidade de aplicar esse mesmo dispositivo em outras atividades para a turma. Por exemplo, na aula seguinte, o tema foi "direitos humanos e instituições", e a metodologia prevista era o uso de um "quebra-cabeça" interativo, no qual deveriam escolher uma instituição qualquer e fazer um relatório sobre ela. Sentindo a motivação e o envolvimento dos alunos, provavelmente resquício da experiência vivida na aula passada, ela incluiu a possibilidade, para aqueles que quisessem, de fazer a atividade no formato de vídeo.

\section{Finalizando...}

Pensando no desafio da criação de desencontradas possibilidades e temporalidades que o ensino de sociologia por meio do cinema provoca, desperta-me para um novo tempo, o tempo da inclusão de ferramentas que já nos são comuns como o smartphone; do reinventar, mesmo em sala de aula com suas dificuldades e desafios, o uso de tecnologias que já fazem parte do nosso dia a dia como aliadas ao processo de ensino-aprendizagem.

E nesse projeto, vivendo a realidade do ensino básico nas escolas públicas, onde sequer se conhece a lei 13.006/2014, o celular, que na última década passou a ser o maior alvo das críticas dos professores, por disputarem a atenção e interesses dos alunos em sala de aula, torna-se uma ferramenta importante, um aliado da educação.

A mudança de postura que o projeto me possibilitou transforma as pequenas reações em grandes ações, a exemplo de alguns alunos mais velhos, aqueles mais distanciados das atividades didático-pedagógicas, pouco motivados, que viram no "uso do celular" uma oportunidade para buscar a integração com a turma e ter maior diálogo com o professor.

A principal proposta do projeto foi fomentar o uso dos recursos cinematográficos em sala de aula, como contribuição a formar sujeitos empoderados em suas realidades, espacialidades e territórios, retratando suas próprias narrativas de forma cinematográfica, e com isso fortalecer a articulação entre o uso de recursos imagéticos e os não imagéticos no ensino de sociologia. A experiência aqui narrada é apenas uma pequena ilustração de como estes recursos podem ser utilizados em sala de aula. Há muito mais a se explorar, 
penso, por exemplo, em como as imagens podem nos levar ao encontro das realidades sócio-históricas e transformá-las em conteúdo vivo/significativo para o ensino da sociologia: fotografias de família, que têm potencial de construção de memórias no sujeito social, as produções imagéticas cotidianas captadas pelo celular etc. Dessa forma, a realidade de cada bairro, cada cidade, família etc. pode fazer parte do currículo escolar e da prática de ensino da sociologia.

O mérito principal pela utilização dos dispositivos cinematográficas no IFPB, relatados nesta experiência, deve-se aos próprios alunos que, a partir de suas realidades, aceitaram o desafio de adaptar as novas tecnologias para uso didático-pedagógico em sala de aula. Aliaram a linguagem da tecnologia já vivida no cotidiano à possibilidade de aprender sociologia produzindo cinema - não somente como espectadores -, mostrando que a utilização de dispositivos cinematográficos como recurso didático é viável no contexto do ensino público e técnico integrado na cidade de João Pessoa/PB.

\section{Referências}

BARQUETE, F. L. O discurso da criação fílmica como mediação da aprendizagem do saber escolar. 2017. Dissertação (Mestrado em Educação) - Programa de PósGraduação em Educação, Universidade Federal da Paraíba, João Pessoa, 2017.

BARRA, Regina Ferreira. Lei 13.006/14: antecedentes históricos e políticos, possibilidades de aplicação e transcriações do cinema na escola. In: ENCONTRO NACIONAL DE DIDÁTICA E PRÁTICAS DE ENSINO - ENDIPE, 18, 2016, Cuiabá. Anais [...] Cuiabá: UFMT, 2016, p. 7779-7814. Disponível em: https://www.ufmt.br/ endipe2016/downloads/233_10279_37599.pdf. Acesso em: 01/05/20.

BRASIL. Presidência da República. Lei no 13.006, de 23 de julho de 2014. Brasília: Presidência da República, 2014. Disponível em: http://www.planalto.gov.br/ccivil_03/ _Ato2011-2014/2014/Lei/L13006.htm. Acesso em: 01/05/20.

MIGLIRORIN, Cezar et al. Cadernos do inventar: cinema, educação e direitos humanos. Niterói/RJ: EDG, 2016

FOUCAULT, Michel. Microfísica do poder. Rio de Janeiro: Edições Graal, 1979

MARTINS, J. de Souza. A imagem incomum: a fotografia dos atos de fé no Brasil. Estudos Avançados, São Paulo, v. 16, n. 45, p. 223-260, 2002. Disponível em: https:// www.scielo.br/scielo.php?script=sci_arttext\&pid=S0103-40142002000200015. Acesso em: 01/05/20.

MARTINS, J. de Souza. Sociologia da fotografia e da imagem. São Paulo: Contexto, 2009. 
MILLS, Wright C. A imaginação sociológica. Rio de Janeiro: Zahar Editores, 1980.

RACHETTI, Luiz G. F. Sociologia e cinema: o uso do audiovisual na aprendizagem de sociologia no ensino médio. 2016. Dissertação (Mestrado em Ciências Sociais) Programa de Pós-Graduação em Ciências Sociais, Universidade Federal do Rio Grande do Norte, Natal, 2016.

SAFFIOTI, Heleiete. O poder do macho. São Paulo: Moderna, 1987.

SILVA, Afrânio et al. Sociologia em movimento. 2. ed. São Paulo: Moderna, 2016.

TERRITÓRIO do Brincar. Produção de Maria Farinha Filmes e Ludus Vídeos. São Paulo: Instituto Alana, 2015. DVD (90 min), son., color.

Recebido em: 20/02/20.

Aceito em: 02/05/20. 